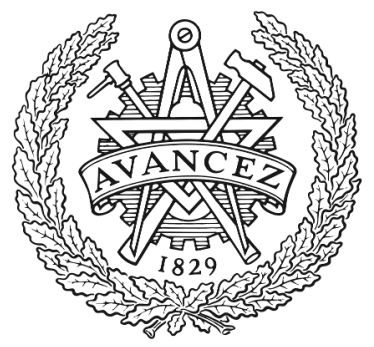

CHALMERS

UNIVERSITY OF TECHNOLOGY

\title{
Solar photovoltaic-battery systems in Swedish households - Self-consumption and self-sufficiency
}

Downloaded from: https://research.chalmers.se, 2023-04-26 15:11 UTC

Citation for the original published paper (version of record):

Nyholm, E., Goop, J., Odenberger, M. et al (2016). Solar photovoltaic-battery systems in Swedish households - Self-consumption and self-sufficiency. Applied Energy, 183: 148-159.

http://dx.doi.org/10.1016/j.apenergy.2016.08.172

N.B. When citing this work, cite the original published paper. 
Solar photovoltaic-battery systems in Swedish households -Self-consumption and self-sufficiency

Emil Nyholm ${ }^{a *}$, Joel Goop ${ }^{\mathrm{a}, \mathrm{b}}$, Mikael Odenbergera,c, Filip Johnsson ${ }^{\mathrm{a}, \mathrm{d}}$

${ }^{a}$ Energiteknik, Chalmers Tekniska Högskola, SE - 41296 Göteborg, Sweden

${ }^{b}$ Email: joel.goop@chalmers.se

'Email: mikael.odenberger@chalmers.se

dEmail: filip.johnsson@chalmers.se

*Corresponding author

Email: emiln@chalmers.se

Tel: +46 317725259 


\section{Abstract}

This work investigates the extent to which domestic energy storage, in the form of batteries, can increase the self-consumption of electricity generated by a photovoltaic (PV) installation. The work uses real-world household energy consumption data (measurements) as the input to a household energy consumption model. The model maximizes household self-sufficiency, by minimizing the amount of electricity purchased from the grid, and thereby also maximizing the level of selfconsumption of PV electricity, i.e., the amount of PV-generated electricity that is consumed in-house. This is done for different combinations of PV installation sizes (measured in array-to-load ratio; ALR: ratio of the PV capacity to the average annual electric load of a household) and battery capacities for different categories of single-family dwellings in Sweden (i.e., northern latitudes). The modeling includes approximately 2000 households (buildings).

The results show that the use of batteries with capacities within the investigated range, i.e., $0.15-100$ $\mathrm{kWh}$, can increase the level of self-consumption by a practical maximum of 20-50 percentage points (depending on the load profile of the household) compared to not using a battery. As an example, for a household with an annual electricity consumption of $20 \mathrm{MWh}$ and a PV installation of $7 \mathrm{~kW}_{\mathrm{p}, \text {, this }}$ range in increased self-consumption of PV-generated electricity requires battery capacities in the range of 15-24 kWh (actual usable capacity), depending on the load profile of the specific household. The practical maximum range is determined by the seasonality of PV generation at Swedish latitudes, i.e., higher levels of increased self-consumption are possible, however, it would require substantially larger batteries than the up to $100 \mathrm{kWh}$ investigated in this work. Thus, any additional marginal increment in battery capacity beyond the range investigated results in a low level of utilization and poor additional value. Furthermore, our results reveal that when a battery is used to store PVgenerated electricity in-house, self-sufficiency increases (as compared to not using a battery) by 12.530 percentage points for the upper range of the investigated PV capacities (ALR of 6).

Keywords: Solar photovoltaics; Batteries; Self-consumption; Self-sufficiency; Households 


\section{Introduction}

The falling cost of solar photovoltaic (PV) panels, as well as subsidy schemes to promote the installation of panels has resulted in increased worldwide deployment of solar PV, with a total of $180 \mathrm{GW}$ being installed globally as of Year 2014 [1]. In addition, the cost of batteries is falling at a higher rate than predicted [2]. Due to their modular nature, both solar PV panels and batteries are well suited for distributed deployment and therefore represent a possible investment for individual households. Investment in a battery system would allow a household to increase self-consumption of its PVgenerated electricity, and thus enhance independence from the grid (i.e., reduced need to purchase electricity from the grid). For instance, for the individual household there could be an economic benefit to increasing self-consumption as shown by Mulder et al. [3]. Given a high enough electricity price there can be a significant value in reducing the amount of electricity the household purchases from the grid. An increase in the amount of self-consumed electricity can also be beneficial for the surrounding electricity system. From the perspective of the operator of the distribution grid (DSO) the batteries can help reduce peak power, reducing the need for grid expansion, and help with voltage regulation [4]. This paper investigates how solar PV and battery installations can be combined within Swedish households so as to maximize PV electricity self-consumption (i.e., usage of the PV electricity generated in-house) and self-sufficiency (the fraction of electricity used by the household that is not purchased from the grid).

Luthander et al. [5] performed an extensive review of the available literature concerning PV electricity self-consumption in buildings. They have proposed definitions of the concepts of PV electricity selfconsumption and self-sufficiency: PV electricity self-consumption is defined as the share of PVgenerated electricity that is consumed in-house; and self-sufficiency is defined as the fraction of consumed electricity that is not bought from the grid. Luthander et al. [5] concluded that while it is obvious that batteries have the potential to increase PV electricity self-consumption, the extent to which this can be achieved varies considerably across the reviewed papers. Widén and Munkhammar [6] and Thygesen and Karlsson [7] have investigated the potential to increase PV electricity selfconsumption in a Swedish context. Widén and Munkhammar [6] studied several battery and PV combinations for a Swedish household. They found that a $5 \mathrm{~kW}_{\mathrm{p}} \mathrm{PV}$ installation coupled with a $3 \mathrm{kWh}$ battery (actual usable energy capacity) increased PV electricity self-consumption by $614 \mathrm{kWh} /$ year. Furthermore, they showed that doubling the battery size increased PV electricity self-consumption by only an additional $358 \mathrm{kWh} /$ year. Thygesen and Karlsson [7] investigated the use of battery installations with capacities in the range of 5-24 kWh (actual usable energy capacity), together with a $P V$ installation of $5.2 \mathrm{~kW}_{\mathrm{p}}$ in a Swedish building. For the extreme cases of batteries with capacities of 5 $\mathrm{kWh}$ and $24 \mathrm{kWh}, \mathrm{PV}$ electricity self-consumption increased by 18 percentage points and 33 percentage points, respectively, relative to not using a battery, indicating a reduced marginal benefit of the additional increase in battery capacity. Weniger et al. [8] investigated a German household and showed that for a PV installation of $1 \mathrm{~kW} / \mathrm{MWh}$, where MWh refers to the annual household consumption, PV electricity self-consumption of $30 \%$ and self-sufficiency of $28 \%$ were reached. With the installation of a battery with capacity of $1 \mathrm{kWh} / \mathrm{MWh}$, the PV electricity self-consumption and selfsufficiency increased to $59 \%$ and $56 \%$, respectively. Mulder et al. [9] investigated seven Belgian households and showed that the optimal storage size (based on their own definition and given in kWh storage per annual PV electricity in MWh) was in the range of 0.4-1.5. Pötzinger et al. [10] modeled a household PV system coupled with hydrogen storage in Germany and showed that for a PV installation of $8.6 \mathrm{~kW}_{\mathrm{p}}, 8 \mathrm{kWh}$ of storage would increase PV electricity self-consumption by 35 percentage points. Several other studies have also presented results concerning self-consumption and self-sufficiency of PV-battery system for German and Belgian households, e.g., Linssen et al. [11], Beck et al. [12], Johann and Madlener [13], de Oliveira e Silva and Hendrick [14], Braun et al. [15], and Schreiber and Hochloff 
[16]. There are also studies with a non-Northern European focus, e.g., Khalilpour and Vassallo [17] investigated the technical and economic potential of a PV-battery system for a household in Sydney, Australia. They showed that an increase in self-sufficiency by 50 percentage points, resulting in final self-sufficiency of around $90 \%$, is possible given a PV installation of $20 \mathrm{~kW}_{\mathrm{p}}$ and a battery size of 15 kWh. Huang et al. [18] investigated the prospect of residential PV-battery systems in California, USA. They showed the reduction in the amount of electricity purchased per day given a PV-panel size of 4 $\mathrm{kW}_{\mathrm{p}}$ and battery sizes ranging from $0.5 \mathrm{kWh}$ to $10 \mathrm{kWh}$. For $0.5 \mathrm{kWh}, 7 \mathrm{kWh}$, and $10 \mathrm{kWh}$ batteries the daily reduction in purchased electricity is $0.79 \mathrm{kWh}, 7.13 \mathrm{kWh}$ and $9.14 \mathrm{kWh}$, respectively. Thus, the reduction in purchased electricity per installed kWh battery diminishes with increasing battery capacity. Castillo-Cagigal et al. [19] studied a prototype of self-sufficient solar house in Spain with a $5.55 \mathrm{~kW}_{\mathrm{p}} \mathrm{PV}$ installation and a battery capacity of $5.4 \mathrm{kWh}$. They also simulated several other batteries capacities together with the PV-panel and the house load. The $5.4 \mathrm{kWh}$ battery improved the PV electricity self-consumption by 41 percentage points during a one week measurement, from $31 \%$ to $72 \%$. From the simulations they showed that a battery capacity equaling the daily electricity consumption of the house results in a self-consumption of almost $90 \%$. Osawa et al. [20] investigated a $3.4 \mathrm{~kW}_{\mathrm{p}} \mathrm{PV}$ system together with a $24 \mathrm{kWh}$ lithium-ion vehicle battery given a typical residential load profile in Tokyo, Japan. They concluded that the battery has the potential to increase self-consumption by 38 percentage points, from $41 \%$ without battery to $79 \%$ with a battery.

In summary, the above-mentioned studies indicate that the ability of batteries to increase PV electricity self-consumption and self-sufficiency decrease with increased battery capacity. However, the different investigations have yielded different results with respect to the extents to which batteries can increase PV electricity self-consumption and self-sufficiency. Furthermore, all of the previous studies investigated a limited number of households and applied different methods. Therefore, there is a need for a systematic approach that use a sufficiently large sample of buildings to give a reasonable representation of a true building stock, such as that for a country. There are also considerable differences between the level of self-consumption and self-sufficiency reached for different geographical locations. Indicating that studies for different latitudes and climates are needed. All of the above mentioned research needs are also identified by Luthander et al. [5], who point to the need for studies that involve a more representative sample of buildings and end-users, i.e., including buildings with different geographic locations and types of households. The present work aims to provide such an analysis, albeit limited to single-family dwellings in Sweden. However, the results should be valid for countries with similar climate and irradiation levels such as Norway, Denmark, and northern Germany.

We provide a comprehensive analysis of how PV electricity self-consumption and self-sufficiency in Swedish single-family households/dwellings with PV installations vary with battery capacity. The study examines 2,104 different households with annual electricity demands in the range of 1.24-44.8 MWh. For each household 122 different combinations of PV sizes and battery capacities are investigated. The combination of a large number of households and PV sizes and battery capacities combinations result in a thorough systematic study, something, that as far as the authors are aware, has not previously been performed. The goal is to illustrate the benefits (in terms of PV electricity self-consumption and self-sufficiency) of different battery capacities across the 2,104 households. The results give insights into the variation in the increase self-consumption and self-sufficiency from installing batteries together with PV-systems in Swedish households. A sensitivity analyses is performed with respect to the power ratings of the batteries in relation to their energy capacities. The method applies in the work is a mathematical model of the household that maximizes self-sufficiency, and thereby also PV electricity self-consumption, albeit without any economic assessment of the potential profitability of investments in PV panels and batteries. 


\section{Modeling}

The evaluation of PV electricity self-consumption and self-sufficiency for a households PV-battery system requires simulation of the PV system together with an optimization of the dispatch of the battery system. The optimization is done over 1 year with a temporal resolution of 1 hour and with perfect foresight. The battery operation is optimized for 122 different combinations of PV and battery sizes for each household, where the sizes of the modelled PV-panel and battery depend on the annual electricity consumption of the household. The load profiles of the 2,104 households modeled are measured load profiles from existing households, while the PV profiles are modeled based on weather data. The battery is modeled using a simplified battery representation of a lithium-ion battery system (as used in [8] and [9]). The simplification implies that the battery is assumed not to self-discharge and that the battery's charge and discharge efficiency is assumed to be constant. Furthermore, the PVbattery system is assumed to be DC coupled, i.e., the PV-panel has a maximum power point tracker and the battery a charge regulator while they share inverter.

\subsection{Optimization}

The optimization step aims at maximizing self-sufficiency for each household, i.e., minimizing the amount of electricity bought from the grid, which in turn maximizes PV electricity self-consumption. The optimization is implemented through dispatch of the charging and discharging of the battery system. When maximizing self-sufficiency, the sizes of the PV system and the battery need to be predefined and limited, as otherwise the maximization of self-sufficiency would always result in a PVbattery system with the largest allowed installation size. For every modeled time-step, the energy balance over the household needs to be fulfilled. In the balance, the demand for electricity can be fulfilled in part or completely through the purchase of electricity from the grid, from electricity generated by the PV system or electricity supplied from the battery system. Using the battery system to satisfy demand obviously requires that the battery has been charged during a previous time-step. The charging and discharging of the battery imply a loss of electrical energy in the form of heat. In the model, this is handled through an assumed (and constant) efficiency of the charging and discharging steps. It should be noted that the optimization is performed at a household level, i.e., the behavior of one household does not impact the behavior of any of the other households.

More formally the model can be defined as follows. The letters that are bold constitutes the variables decided on by the model.

The optimization model minimizes the total amount of bought electricity:

$$
\min \boldsymbol{E}_{\text {tot }}=\sum_{h \in H} \sum_{t \in T} \boldsymbol{e}_{h, t}^{b o t}
$$

where $H$ is the set of all modeled households and $T$ is the set of all time steps. The term $\boldsymbol{e}_{h, t}^{b o t}$ is the electricity purchased by household $h$ at time step $t$.

To ensure that the electricity demand is met for each household the optimization is subject to:

$$
d_{h, t}+\boldsymbol{e}_{h, t}^{\text {sold }}+\boldsymbol{s}_{h, t}^{a d d}=\boldsymbol{e}_{h, t}^{b o t}+p_{h, t}+\boldsymbol{s}_{h, t}^{r e m} \times \eta^{b a t} \quad \forall h \in H, t \in T
$$

where $d_{h, t}$ is the electricity demand from household $h$ at time $t$. The term $s_{h, t}^{a d d}$ is the energy added to the battery and $s_{h, t}^{r e m}$ is the energy removed from the battery for household $h$ at time $t$. The 
energy removed is multiplied with the battery discharge efficiency, $\eta^{\text {bat }}$, to capture energy losses from operating the battery. Further, $p_{h, t}$ is the electricity generated by a PV-panel belonging to household $h$ at time $t$.

The energy storage level of the batteries is subject to:

$$
\boldsymbol{l}_{h, t}=\boldsymbol{l}_{h, t-1}-\boldsymbol{s}_{h, t}^{r e m}+\boldsymbol{s}_{h, t}^{a d d} \times \eta^{b a t} \quad \forall h \in H, t \in T
$$

where $l_{h, t}$ is the storage level of a battery belonging to household $h$ at time $t$. The storage level and the charge and discharge capacity are subject to:

$$
\begin{aligned}
& \boldsymbol{s}_{h, t}^{r e m} \leq c_{h} \quad \forall h \in H, t \in T \\
& \boldsymbol{s}_{h, t}^{a d d} \leq c_{h} \quad \forall h \in H, t \in T \\
& \boldsymbol{l}_{h, t} \leq b_{h} \quad \forall h \in H, t \in T
\end{aligned}
$$

where $c_{h}$ is the power capacity of the battery and $b_{h}$ the energy capacity of the battery in household $h$. All variables can only assume positive values:

$$
\boldsymbol{e}_{h, t}^{b o t} ; \boldsymbol{e}_{h, t}^{\text {sold }} ; \boldsymbol{s}_{h, t}^{\text {add }} ; \boldsymbol{s}_{h, t}^{r e m} ; \boldsymbol{l}_{h, t} \geq 0
$$

\subsection{Definition of PV electricity self-consumption and self-sufficiency}

After the optimization of the dispatch of the battery system the PV electricity self-consumption and self-sufficiency for each modeled case are calculated. We apply the definition of PV electricity selfconsumption and self-sufficiency proposed by Luthander et al. [5]. In their definition, the term $M(t)$ represents the generated electricity (either from the PV installation or the battery) used in-house in every instance; this is simply the smallest value of the two terms $L(t)$ and $(P(t)+S(t))$ for an instantaneous moment and is given by:

$$
M(t)=\min \{L(t), P(t)+S(t)\}
$$

where $L(t)$ denotes the instantaneous household electricity load, $P(t)$ is the instantaneous PV electricity generation, and $S(t)$ is the instantaneous power to or from the battery storage, i.e., when the storage is charging $S(t)<0$ and when it is discharging $S(t)>0$. If the battery is neither charged nor discharged $S(t)$ equals zero. It should be noted that only useful energy is considered in the charging/discharging term, i.e., the energy lost as heat in charging/discharging is not included in the energy considered as self-consumed. Furthermore, the battery is used exclusively for storing PVgenerated electricity, i.e., it cannot be used for arbitrage on the electricity market. Integrating Eq. (8), which refers to the in-house use of generated electricity, over a time period divided by the PV power generation integrated over the same period gives the PV electricity self-consumption: 


$$
\varphi_{s c}=\frac{\int_{t=t_{1}}^{t_{2}} M(t) d t}{\int_{t=t_{1}}^{t_{2}} P(t) d t}
$$

This work applies an integration period of 1 year in order to capture seasonal variations in load and PV-generated electricity.

Replacing $\mathrm{P}(\mathrm{t})$ with the load $\mathrm{L}(\mathrm{t})$, self-sufficiency is expressed as:

$$
\varphi_{s S}=\frac{\int_{t=t_{1}}^{t_{2}} M(t) d t}{\int_{t=t_{1}}^{t_{2}} L(t) d t}
$$

Although the above formulations call for a continuous integration of the values over the time period investigated, the input data used are discrete with an hourly resolution.

\subsection{PV and battery system sizing}

As the investigated households show large variations in their annual levels of electricity consumption, comparing the absolute size of the PV-battery system between households would make it difficult to analyze the impact of the PV-battery system on PV electricity self-consumption and self-sufficiency. Therefore, the sizes of the investigated PV-battery systems for each household are related to the individual electricity demands of the households. The rated power of the PV installations is expressed as the Array-to-Load ratio (ALR) [21]:

$$
A L R=\frac{\text { array size }\left(W_{p}\right)}{\text { average annual load }(W)}
$$

The ALR relates the average household load during a time period to the peak-Watt value of the installed PV system. As indicated above, the time period applied in this work is 1 year, so as to include seasonal variations in demand. Correspondingly, the rated energy storage capacity of the batteries is expressed as the Battery-to-Demand ratio (BDR):

$$
B D R=\frac{\text { battery energy capacity }(W h)}{\text { annual average hourly demand }(W h)}
$$

Thus, the BDR relates the energy storage capacity of the battery to the annual average hourly demand of the household. The investigated battery sizes reflect the usable share of the installed battery, which means that this work does not include assumptions as to the limits of the depth of discharge. The rated power of the batteries is assumed to be ${ }^{*} \mathrm{E}$, where $\mathrm{E}$ is the rated energy of the battery, i.e., a battery with a rated energy of $2 \mathrm{kWh}$ would have a rated power of $2 \mathrm{~kW}$. Values of $0.25 \mathrm{E}, 0.5 \mathrm{E}$, and $0.75 \mathrm{E}$ are also investigated, which correspond to rated powers of $0.5,1.0$, and $1.5 \mathrm{~kW}$ for a $2-\mathrm{kWh}$ battery, respectively. Given that the modeled time step is 1 hour, the investigation of rated power values $>1 \mathrm{E}$ is not meaningful, since such power ratings imply the emptying of a fully charged battery in less than 1 hour, which in reality could be interesting but is not relevant to this study.

To relate the installed battery size to the electricity generated by the installed PV system, the relative battery capacity is used. The Relative Battery Capacity (RBC) is defined as the battery size (in kWh) relative to the annual output of the PV panels (in MWh) and is written as: 


$$
R B C=\frac{\text { battery energy capacity }(W h) \times 1000}{\text { annual generated } P V \text { electricity }(W h)}
$$

The concept of RBC has previously been used by Luthander et al. [5], Weniger et al. [8] and Mulder et al. [9]. However, these authors do not provide a strict definition of the concept; thus, we propose the use of relative battery capacity.

\section{Data}

\subsection{Household loads}

The household demand in the model is represented by the measured hourly load profiles from a total of 2,104 Swedish single-family dwellings. Each measured point represents the total electricity consumption during the measured hour for the specific household. The households were measured over a 1-year period (February 1, 2012 to January 31, 2013) as part of a Swedish household measurement project conducted by E.ON. The total number of measured households in the project was 10,086 . However, those households that are missing $\geq 5 \%$ of the measurement points and households for which information regarding geographical location was not collected are removed from the dataset, with the result that 2,104 household are included in the modelling. The primary cause for the reduction is the lack of geographical location information.

For the optimization, each household requires an electricity demand for each time-step. Since the 2,104 households still have up to $5 \%$ of their data-points missing, the missing data-points for these households are added. For a given household, this is done by replacing the missing data-points for a given time period with data-points from the closest preceding time period for which there are data from the same household. For example, if 24 hours of data (i.e., 24 data-points) are missing, then datapoints from the preceding 24-hour period are used to replace the missing data. Care is taken to ensure that a missing hour is replaced with the corresponding hour, i.e., missing data for 12:00 are replaced with data collected at 12:00 the previous day. Similarly, weekday hours are replaced with other weekday hours and weekend hours are replaced with the corresponding weekend hours.

The measured households are all situated south of latitude $62^{\circ}$ north, with the majority being situated south of latitude $60^{\circ}$ north, which means that these household are only representative for a part (the southern one-third) of Sweden. Nonetheless, $81 \%$ of the total Swedish electricity demand and $89 \%$ of the Swedish single-family dwellings are located in this area. The annual electricity demand for these households is in the range of 1.24-44.8 MWh. The measured households consist of row houses and detached houses. Furthermore, they have different types of heating systems: either electric-based (heat pumps and direct electric heating) or non-electric (domestic boilers and district heating). Thus, for some households, the heating system is part of the electric load, whereas for other households it is not.

\subsection{Model inputs}

Table 1 lists the model inputs related to the PV and battery systems. The PV systems are assumed to be polycrystalline silicon panels and are assumed to be facing southwards and tilted at $31^{\circ}$ (representing the average house-roof tilt). The outputs of the installed PV systems are based on the modeling framework established by Norwood et al. [22], which in turn use a model verified by King et al. [23]. A degradation efficiency is applied to the PV panels, to represent lifetime degradation. The solar irradiation and temperature data used are from 20 different sites and is typical meteorological year data with an hourly resolution [24]. The battery efficiency is based on the values for lithium iontype batteries, and the same efficiency is applied to charging and discharging. Thus, the roundtrip efficiency of the battery is simply the square of the battery efficiency. The PV and battery are also 
assumed to be on the same side of the inverter (DC-coupled system), i.e., the inverter efficiency is only applied once.

Table 1. Input data for the PV and battery systems used in the model. Additional input for the PV-model can be found in Norwood et al. [22].

\begin{tabular}{l|l}
\hline Input parameter & Input value \\
\hline Inverter efficiency & $0.95[25]$ \\
Panel orientation & Due south \\
Panel tilt & $31^{\circ}[26]$ \\
Degradation & $0.98[27]$ \\
Annual generated PV electricity (the range represents & $901-1070 \mathrm{kWh} / \mathrm{kW}_{\mathrm{p}}[22],[24]$ \\
the different locations) & $0.95(0.90)[28]$ \\
Battery efficiency (roundtrip) &
\end{tabular}

A range of combinations of ALRs and BDRs is investigated. The model applies ALR values of between 0.5 and 6.0 in steps of 0.5 , and BDR values of between 0.5 and 20.0 in steps of 0.5 and 1.0. The ALR range corresponds to PV sizes between $0.1 \mathrm{~kW}_{\mathrm{p}}$ to $30.6 \mathrm{~kW}_{\mathrm{p}}$ (depending on household) and the BDR range corresponds to battery sizes between $0.15-100 \mathrm{kWh}$ (depending on household). Not all the BDR values are modeled for each ALR, as this results in either too large a battery or too small a step-change in battery size compared to the PV installation. The modeled combinations are chosen so as to attain a step-change for the relative battery capacity of around 0.3 . In total 122 different combinations of PV and battery sizes are investigated for each household with the sizes of each combination being dependent on the annual electricity demand of the household.

\section{Results}

The results for the PV electricity self-consumption and the self-sufficiency are presented both in terms of absolute percentage values and in terms of how many percentage points the self-consumption and self-sufficiency increase relative to a baseline case (i.e. the arithmetic difference between the investigated case and the baseline case). The baseline is defined as a system with the same ALR as the investigated case but without any battery installed.

\subsection{PV electricity self-consumption}

Three factors will limit the extent to which a household battery system can increase PV electricity selfconsumption of PV-generated electricity: 1 ) the energy capacity of the battery; 2 ) the power capacity of the battery; and 3) the capacity of the PV panel. Which of these acts as the limiting parameter depends on the size configuration of the PV panel and battery and the shape of the household load curve.

Figure 1 shows the percentage point (pp) increases in PV electricity self-consumption for the 2,104 households, as obtained from the modeling. Each pp increase is relative to a case without a battery installed (the baseline referred to above) plotted against the relative battery capacity. Each dot represents one of the 2,104 modeled households and the color code represents the ALR value. An increase of approximately 18-48 pp in PV electricity self-consumption is the maximum reached for the investigated households, given the investigated battery capacities. This level is reached at a relative battery capacity of around 2.5-4 (the corresponding size in kWh ranges from 1.6-100 kWh depending on ALR and household) for all households at ALRs $\geq 4.5\left(0.64-23.0 \mathrm{~kW}_{\mathrm{p}}\right)$. As $100 \%$ self-consumption is not reached at these ALRs, increasing the battery size further would increase self-consumption. However, this increase would be negligible. The resulting absolute values for the PV electricity selfconsumption for ALRs $0.5\left(0.07-2.55 \mathrm{~kW}_{\mathrm{p}}\right), 1.5\left(0.21-7.65 \mathrm{~kW}_{\mathrm{p}}\right), 3\left(0.42-15.3 \mathrm{~kW}_{\mathrm{p}}\right)$, and 6 (0.85-30.6 
$\mathrm{kW}_{\mathrm{p}}$ ) are shown in Figures 2, with each dot representing one of the modeled households and the lines representing the median household in terms of PV electricity self-consumption., For the median household, PV electricity self-consumption range from $65 \%$ to almost $100 \%$, depending on the ALR. However, as can be seen the spread in PV electricity self-consumption between households for a given ALR is considerable. It should be noted that $100 \%$ PV electricity self-consumption cannot be reached through the help of a battery, this as there are energy losses associated with operating the battery. However, in Figure 2, it is clear that $100 \%$ PV electricity self-consumption is reached for some households at an ALR of 0.5 (purple dots situated above the median ALR 0.5 line), i.e. for these households there is no need for a battery.

Furthermore, as shown in Figure 1 there is a clear connection between increased battery capacity and increased PV electricity self-consumption for almost all the ALRs. The only exception is the households previously mentioned that at an ALR of 0.5 already consume all their PV-generated electricity in-house. All the households that show an increase in PV electricity self-consumption with increased battery capacity yield diminishing returns with increased relative battery capacity, i.e., each addition of battery capacity leads to less-frequent utilization. As a result, an increase in relative battery capacity from 3 (1.92-90 kWh) to 4 (2.56-100 kWh) increases PV electricity self-consumption by at most $3 \mathrm{pp}$, whereas an increase in relative battery capacity from $2(1.28-61 \mathrm{kWh})$ to 3 results in a corresponding increase of $10 \mathrm{pp}$, as shown in Figure 1 . The reason for the decreasing marginal benefit with increasing battery capacity is the relationship between the electricity load profile and the PV electricity generation profile. One of the factors that reduces the marginal benefit of adding battery capacity is that it is likely that there will be fewer occasions on which energy has to be moved from a period of excess generation to a period without excess generation, i.e., on some days, the existing battery can handle all the excess PV generation, rendering the extra battery capacity redundant during these periods. Furthermore, for sufficiently large ALRs, a further increase in battery capacity will eventually result in a battery that can store more than enough energy to meet the nightly demand during days in which daytime excess PV generation is higher than the night-time demand. As a result, the battery will not be completely emptied before the next period of charging. As a consequence of the battery not being fully discharged, some of the excess PV electricity generated during the following day may not be stored. As battery sizes increase further, the energy has to be stored for longer and longer time-frames, further decreasing the utilization time of the added battery capacity. Eventually, seasonal storage will be required, which obviously increases battery size far beyond the point at which additional capacity has merely an insignificant impact on the PV electricity self-consumption.

Obviously the increase in PV electricity self-consumption can also be limited by the fact that the households have attained $100 \%$ self-consumption. In Figure 2 , it can be seen that for ALRs of $\leq 3$, the increase in self-consumption at high relative battery capacities has stalled for some households. These households have reached their theoretical maximum in terms of self-consumption, i.e., due to the losses from charging/discharging, a higher level of self-consumption cannot be reached. This maximum is reached by households up to an ALR of $4\left(0.57-20.4 \mathrm{~kW}_{\mathrm{p}}\right)$. For ALRs $\geq 4.5$, the theoretical maximum PV electricity self-consumption is never reached for any household, i.e., for all households with ALRs $\geq 4.5$, PV electricity self-consumption is limited by the battery capacity. Furthermore, for the median household in terms of degree of PV electricity self-consumption the theoretical maximum PV electricity self-consumption is only reached for ALRs $\leq 1.5$. This indicates that for ALRs $>1.5$, battery capacity is the limiting factor for increased PV electricity self-consumption in the median household, given the battery capacities investigated here. 


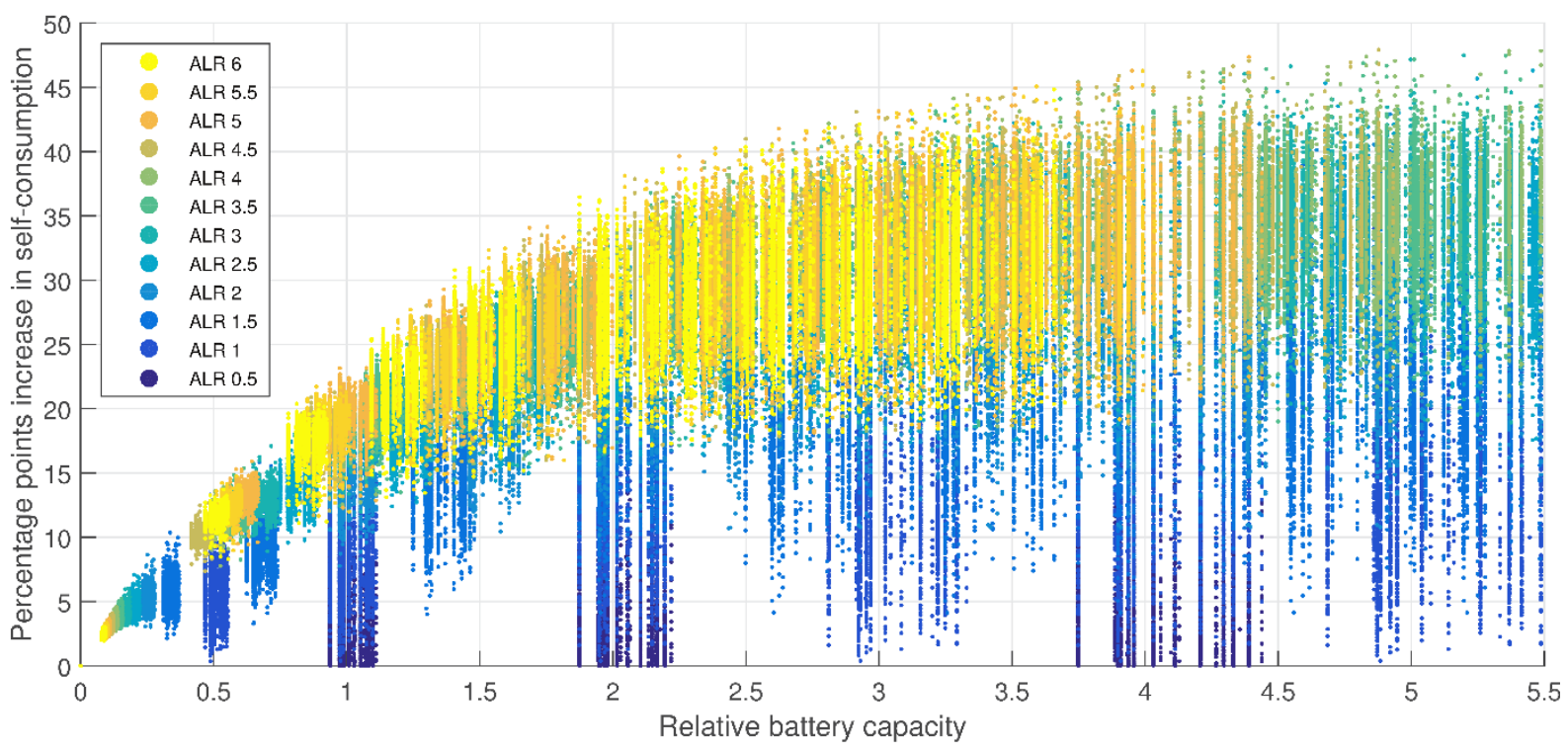

Figure 1. Percentage point increases in PV electricity self-consumption for residential PV systems with batteries compared to a system without batteries, plotted against the relative battery capacity. Each point represents a modeled household and the color coding represents the ALR value.

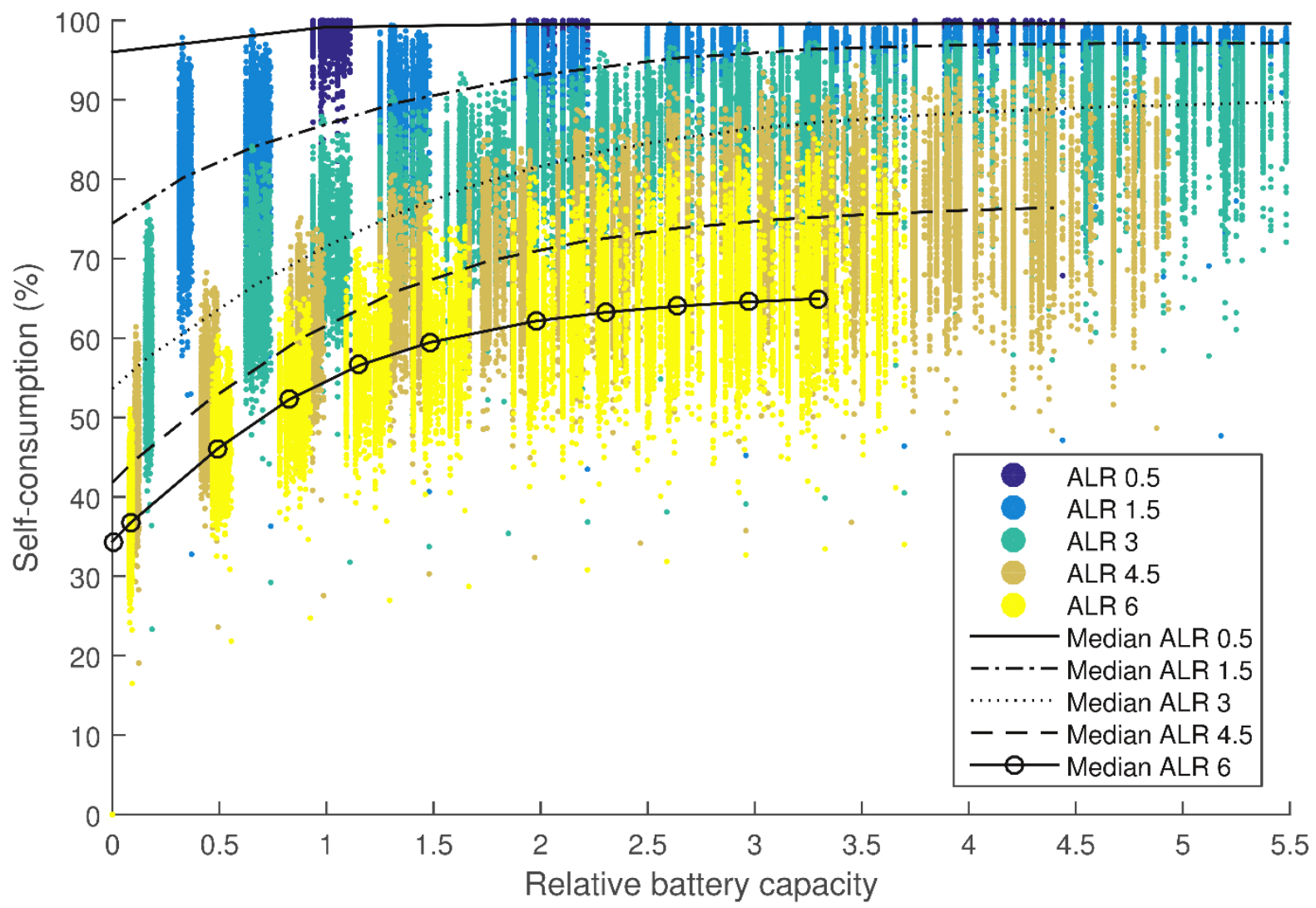

Figure 2. PV electricity self-consumption (in percent) for four different ALRs, plotted against the relative battery capacity. Each point represents a modeled household and the lines gives the median value for the given ALR.

As shown in Figure 1 there is a difference between the households with respect to the pp increase in PV electricity self-consumption for a given relative battery capacity. Furthermore, it can be seen that this difference grows with increasing battery capacity. For lower ALRs, in the range of $0.5-1.5$, this large spread in the increase in PV electricity self-consumption between households is already seen at 
small battery sizes, e.g., at an ALR of $1\left(0.14-5.10 \mathrm{~kW}_{\mathrm{p}}\right)$, the increase varies in the range of $0.5-20 \mathrm{pp}$ at a relative battery capacity of 1 .

The spread in increases in PV electricity self-consumption between households can be attributed to the impact of the households' load profiles. The smaller spread at smaller battery capacities seen for most ALRs is due to that in the case of a small battery, all the households can use the battery in a fairly similar manner, primarily shifting energy from day-time to night-time and thereby achieving similar increases in PV electricity self-consumption. However, as the battery capacity grows the household's ability to utilize the battery starts to differentiate. Figure 3 shows the increase in PV electricity selfconsumption plotted against the relative battery capacity for ALR 1 (a), ALR 3 (b), and ALR 6 (c). Each dot represents one of the modeled households and the color of the dot represents the degree of PV electricity self-consumption at a relative battery capacity of 0 , i.e., the self-consumption for a PV-panel without battery. For an ALR of 1 (Fig 3a), it can be seen that the level of increase in PV electricity selfconsumption depends on the degree of self-consumption at a relative battery capacity of 0 . For example, a high initial PV electricity self-consumption, corresponding to the brighter dots, correlates with a smaller pp increase in self-consumption with increasing battery capacity. This correlation is due to the fact that household's with a high initial self-consumption are reaching or almost reaching total PV electricity self-consumption. Thereby, making impossible to increase PV electricity consumption further. The households with high initial self-consumption tend to be households with non-electricity based heating systems, although all household types can show this behavior. The households with low initial PV electricity self-consumption can increase their self-consumption more since they have more excess electricity generation to move with the help of the batteries. At the higher ALRs (Figs. 3b and c) the connection between the degree of self-consumption at a relative battery capacity of 0 and the increase in self-consumption with increasing battery capacity becomes less obvious. At an ALR of 3 there is still a trend that households with a high initial PV electricity self-consumption have a lower increase in PV electricity self-consumption. And as can be seen in Figure 2 some of these households are still limited in their increase in PV electricity self-consumption due to reaching total selfconsumption. For an ALR of 6 (Fig. 3c) it can be seen that trend is reversed, with a low initial PV electricity self-consumption resulting in a lower increase in self-consumption with increasing battery capacity. The reversed trend can be attributed to skewed load profiles of the households with low initial in PV electricity self-consumption, primarily for households with some form of electric heating. At higher ALRs these households have considerable excess PV electricity generation during summer months. This as their high total electricity demand results in large PV-panels for a given ALR. However, as the electricity demand is low during summer (no electric heating required during those months) there is a large difference between electricity demand and electricity generation. This requires energy to be shifted during longer time frames, i.e., there is not enough night-time electricity demand to empty the battery, resulting in lower battery utilization. At the same time the increase in PV electricity self-consumption for the households with high initial PV electricity self-consumption is no longer limited due to reaching total self-consumption, enabling them to increase their self-consumption further. 


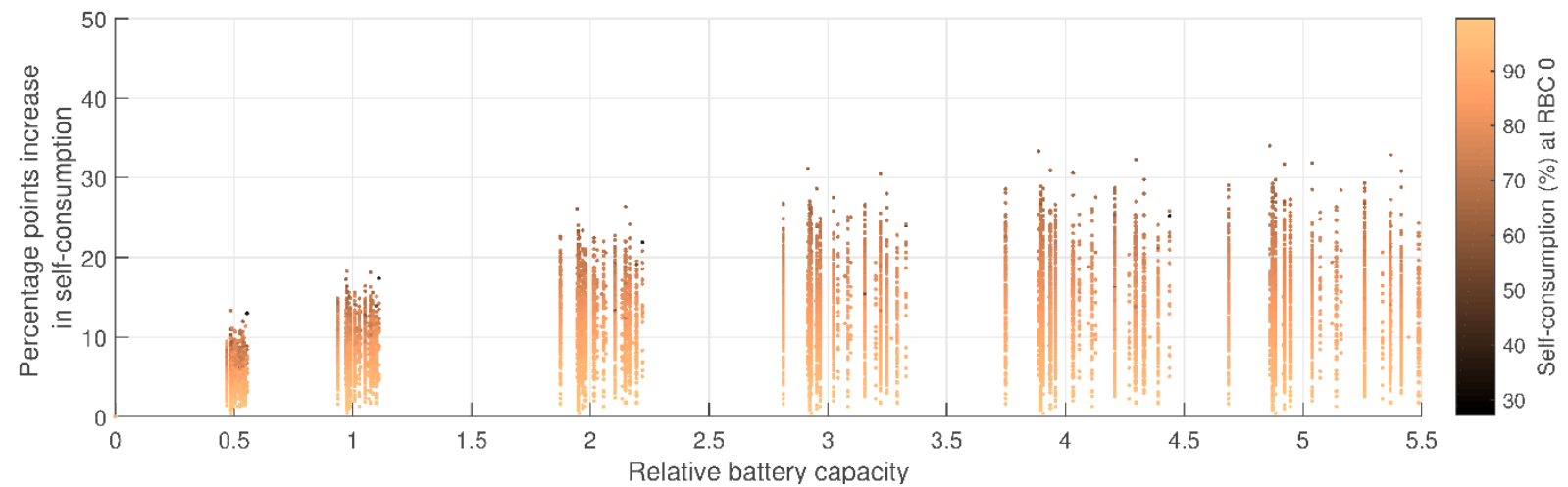

a)

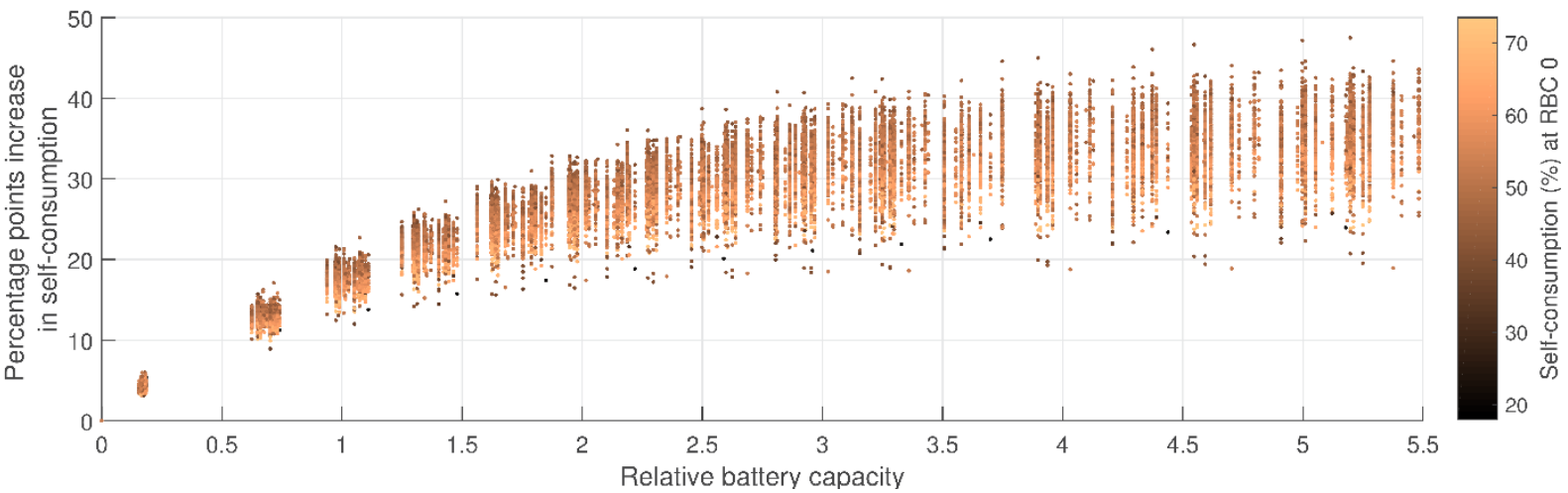

b)

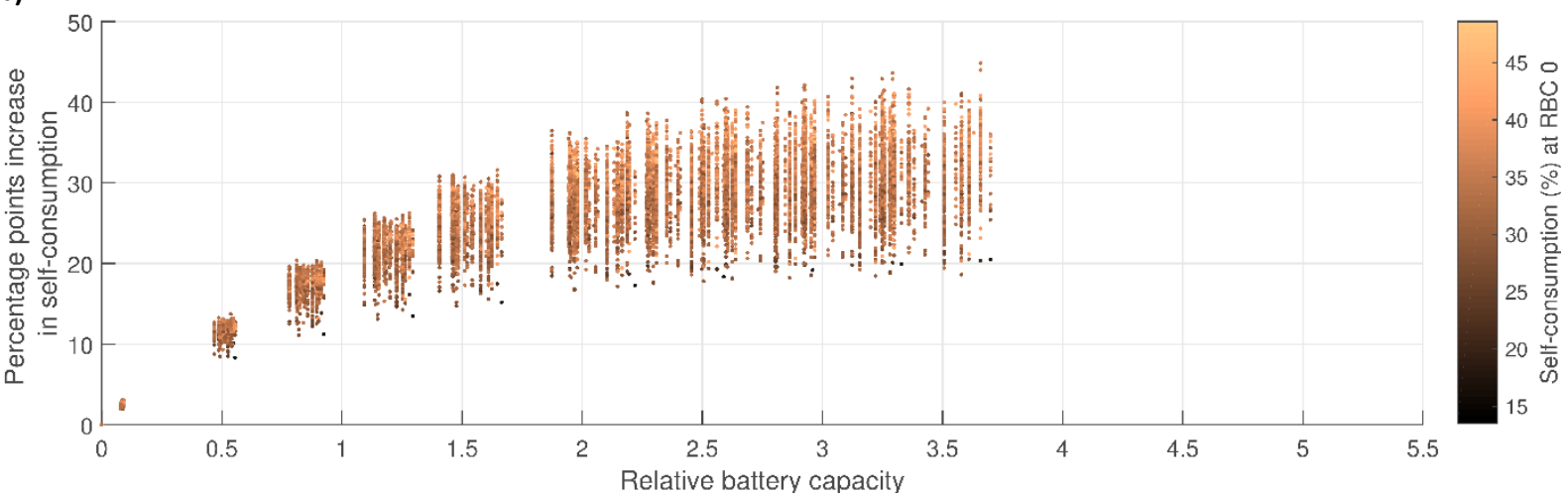

c)

Figure 3. Percentage point increases in PV electricity self-consumption for residential PV systems with batteries compared to a system without batteries for ALR1 (a), ALR3 (b), and ALR6 (c), plotted against the relative battery capacity. Each point represents a modeled household and the coloring represents the degree of self-consumption (\%) for a case without batteries (observe that the scale for self-consumption (\%) is different in figure $a, b$, and $c$ ).

\subsection{Self-sufficiency}

The pp increase in self-sufficiency, i.e., the amount of annual household demand that is met by PVgenerated electricity, is obviously tied to the ability of the battery to increase PV electricity selfconsumption, as well as the size of the PV panel. Figure 4 shows the pp increase in self-sufficiency relative to a case without any battery installed, plotted against the relative battery capacity. As in Figure 1, each dot represents a modeled household and the colors represent the ALR values. Analogous to the PV electricity self-consumption, the pp increase in self-sufficiency levels off with increasing relative battery capacity. However, the impact of the ALR is also evident, with higher ALRs resulting in larger increases in self-sufficiency, as more energy is being shifted for a given relative battery capacity. 
Thus, the highest pp increase in self-sufficiency is seen for an ALR of 6, with the increase in selfsufficiency in the range of 12.5 to $30 \mathrm{pp}$ depending on the household. This increase occurs at a relative battery capacity of 2.5-4.0 depending on the household. If a higher ALR was to be investigated, this would result in a larger increase in self-sufficiency.

However, as the ALR increases, the difference in absolute self-sufficiency between the ALR cases decreases. This becomes evident when one looks at the actual levels of self-sufficiency. Figure 5 shows the resulting absolute values for self-sufficiency for ALRs $0.5,1.5,3$, and 6 , with each dot representing one of the modeled households and the lines representing the median household in terms of selfsufficiency.. As shown in the figure, in the absence of a battery (values of the median household at relative battery capacity 0 ), the difference in the degree of self-sufficiency between ALRs becomes smaller with increasing ALR, e.g., an increase in ALR from 3 to 4.5 increases self-sufficiency by 3 pp, while an increase in ALR from 1.5 to 3 results in an increase in self-sufficiency of $7 \mathrm{pp}$. This phenomenon is explained by the concentrated electricity generation profiles of the PV panels previously discussed, as the PV panel size is increased most of the new generation occurs during hours with excess generation.

For the median household one can see that the self-sufficiency varies between $6 \%$ for an ALR of 0.5 and $45 \%$ for an ALR of 6 , while for the household that shows the highest degree of self-sufficiency, the corresponding values are $7 \%$ and $60 \%$, respectively.

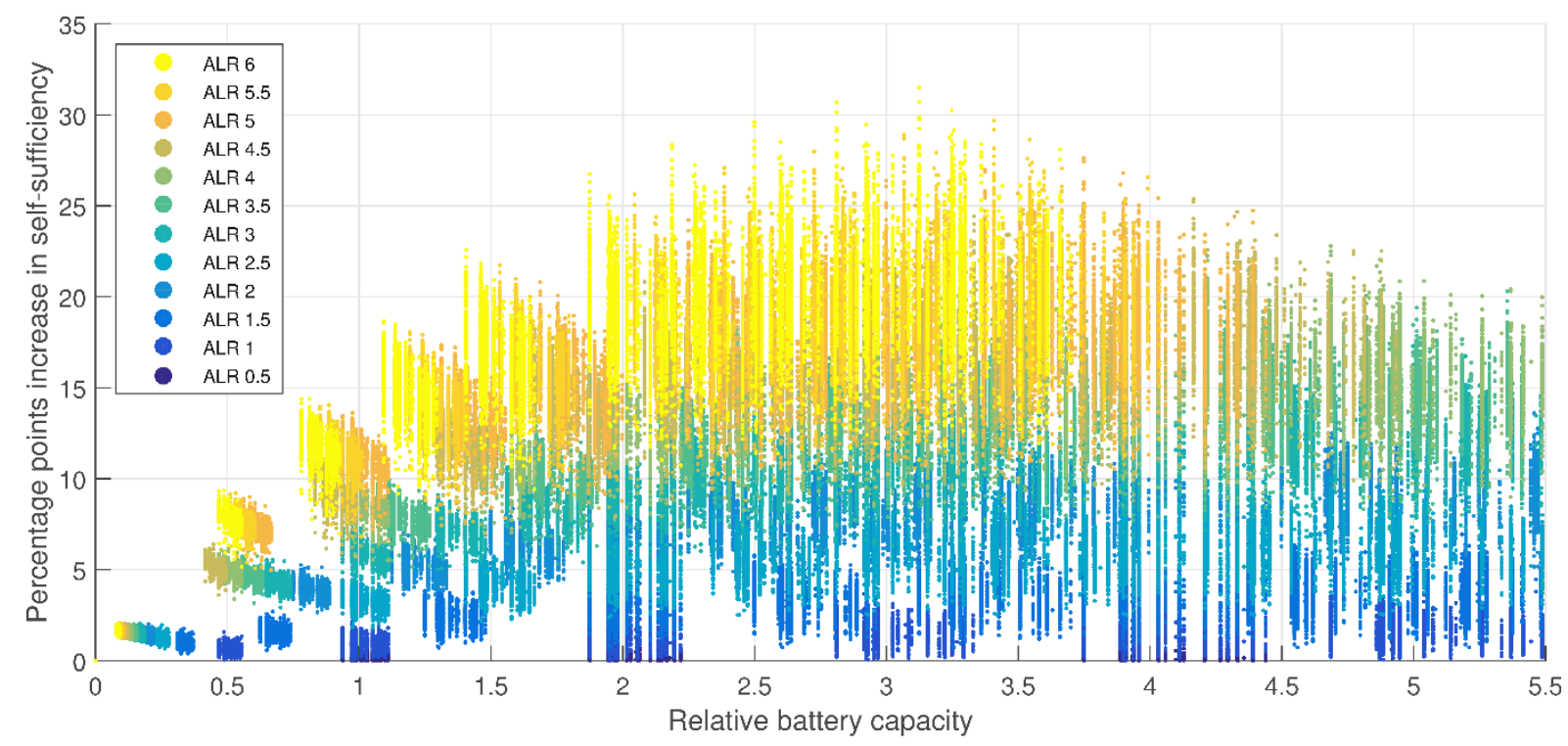

Figure 4. Increases in self-sufficiency for residential PV systems with batteries relative to a system without batteries, plotted against the relative battery capacity. Each point represents a modeled household and the color represents the ALR value. 


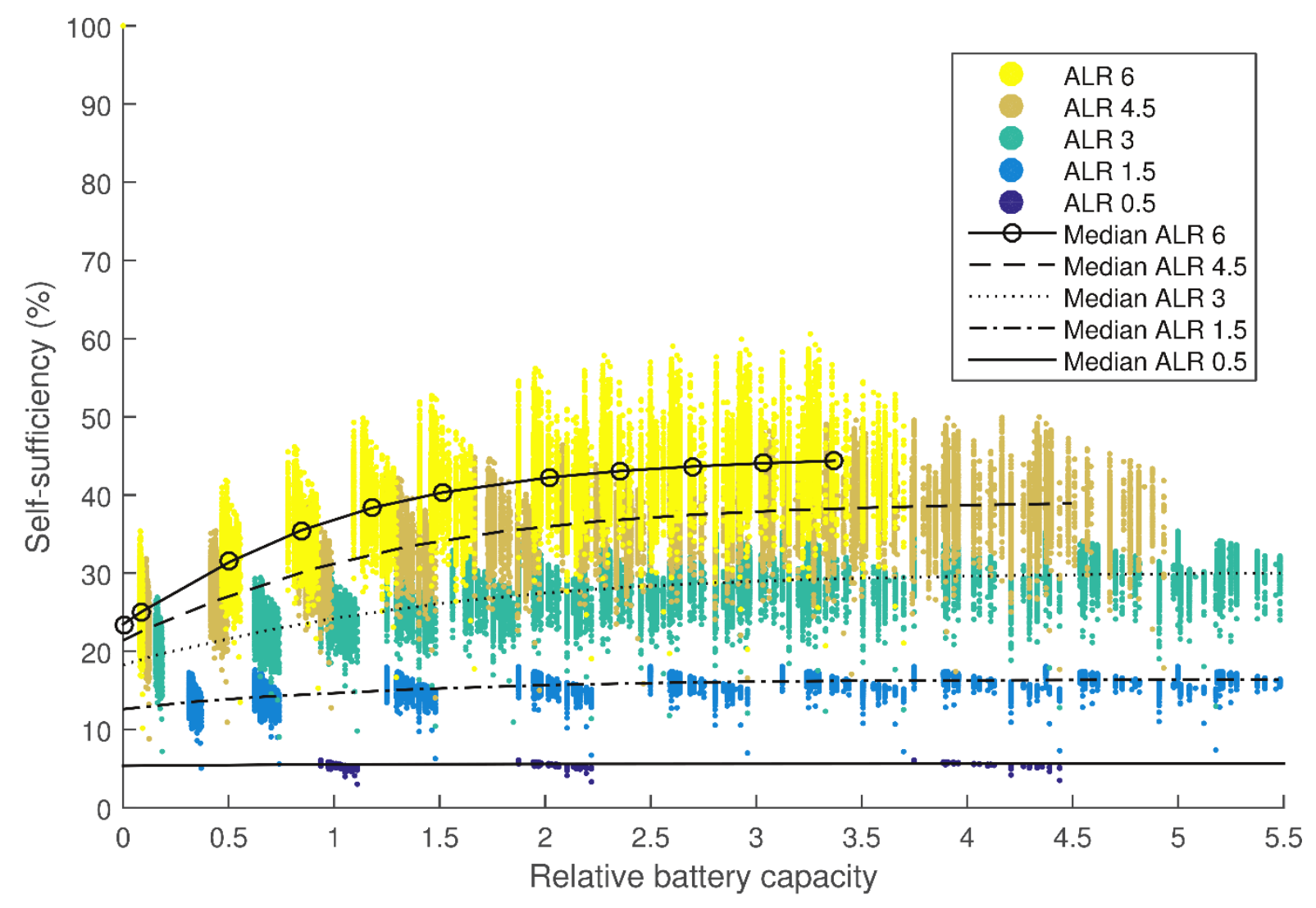

Figure 5. Self-sufficiency (in percent) for four different ALRs, plotted against the relative battery capacity. Each point represents a modeled household and the lines gives the median value for the given ALR.

\subsection{PV panel and battery capacities for Swedish households}

Figure 6 shows the battery capacity in kWh at a relative battery capacity of 1 for ALR values of 1, 3, and 6 , plotted against the annual electricity consumption for all the investigated households. From this figure, the expected battery capacity at a given ALR can be deduced. As an example, at an annual consumption of $25 \mathrm{MWh}$, the installed battery capacity would be in the range of 2.7-3.0 kWh given an ALR of 1 and relative battery capacity of 1 . There is an increased spread in battery capacity between households as annual electricity consumption increases. The spread is due to the fact that the PV installation sizes at a given ALR depend on the annual household electricity consumption. As the size of the PV installation expands with increasing annual consumption, the variation in annual PV electricity generation, which is due to differences in geographical location, becomes more pronounced. Consequently, as the relative battery capacity depends on the annual PV electricity generation, the attained range in generated electricity will translate to a spread in battery capacity at a given relative battery capacity. Figure 7 shows the PV capacities in $k W_{p}$ for ALR $1, A L R 3$, and ALR 6 for any given annual electricity consumption up to $45 \mathrm{MWh}$ per year. Obviously, the relationship depicted in Figure 7 is linear, as the ALR depends only on household consumption and the rated peak power of the panels. 


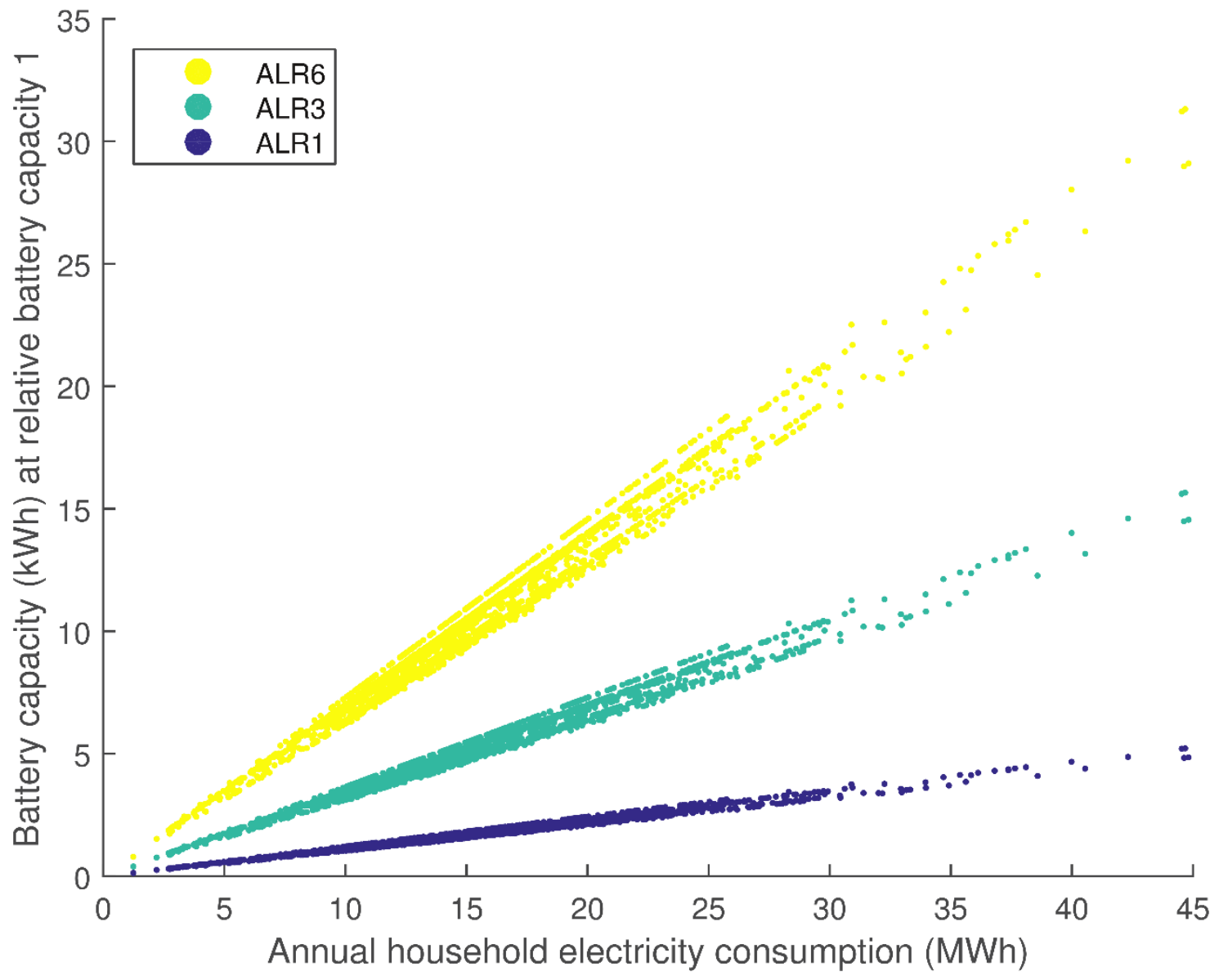

Figure 6. Battery capacity (in kWh) for ALR values of 1, 3, and 6 and a relative battery capacity of 1 plotted against the investigated households' annual electricity consumption. Each point represents a modeled household and the color represents the ALR value. 


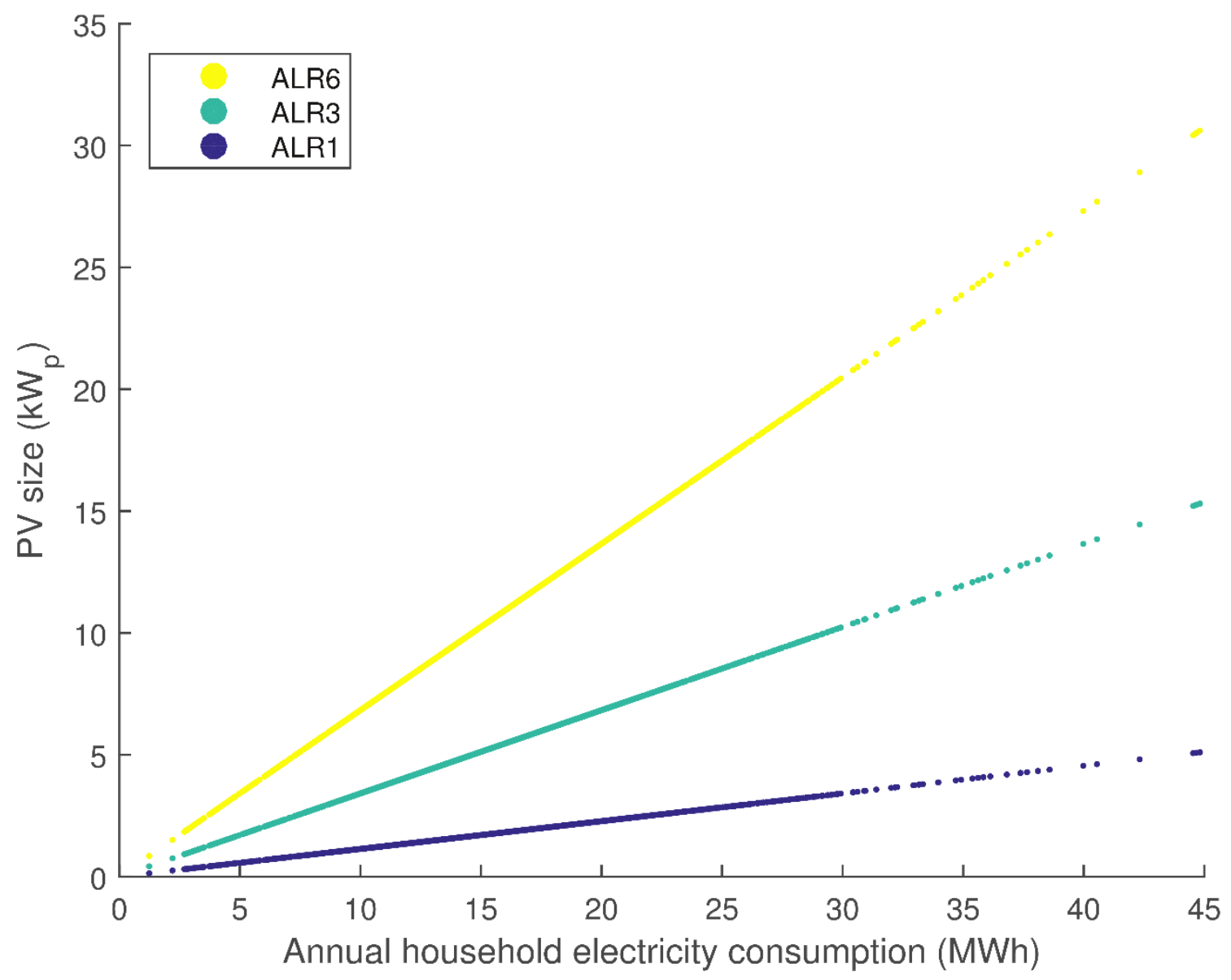

Figure 7. PV size (in $\mathrm{kWp}$ ) for ALR values of 1, 3, and 6 plotted against the investigated households' annual electricity consumption. Each point represents a modeled household and the color represents the ALR value.

Table 2 exemplifies the PV panel size, battery capacity, PV electricity self-consumption and selfsufficiency levels for eight different PV panel-battery combinations in three of the households investigated, each of which has one of the following heating systems (with indicated level of electricity consumption): air heat pump (medium); direct electric heating (high); and pellet boiler (low). These households should not be seen as representative of any group of households. The households with the low and medium annual electricity consumption levels show similar values for PV electricity selfconsumption, although the difference widens for the ALR 6 cases with a battery. The difference in selfsufficiency between a case with an ALR of 3 and relative battery capacity of 1.5 and a case with ALR of 6 and no battery is small at $2 \mathrm{pp}$ each for the heat pump-using and direct electric-using households, making these two setups almost equivalent in this aspect. It should also be noted that at a relative battery capacity of 3 , a relative battery capacity for which practically no increase in PV electricity selfconsumption is gained from an additional increase in battery capacity for all the households (as shown in Figure 1), the resulting battery capacity is substantial.

Table 2. The PV size, battery capacity, and PV electricity self-consumption and self-sufficiency levels for three different households in Sweden. The values are given for various ALRs and relative battery capacities (R.Bat). The annual electricity consumption and type of heating system used in the households are also listed.

\begin{tabular}{|l|l|c|c|c|c|c|c|c|c|}
\hline Household & & $\begin{array}{l}\text { ALR 1/ } \\
\text { R.Bat 0 }\end{array}$ & $\begin{array}{l}\text { ALR 1/ } \\
\text { R.Bat 1 }\end{array}$ & $\begin{array}{l}\text { ALR 3/ } \\
\text { R.Bat 0 }\end{array}$ & $\begin{array}{l}\text { ALR 3/ } \\
\text { R.Bat 1.5 }\end{array}$ & $\begin{array}{l}\text { ALR 3/ } \\
\text { R.Bat 3 }\end{array}$ & $\begin{array}{l}\text { ALR 6/ } \\
\text { R.bat 0 }\end{array}$ & $\begin{array}{l}\text { ALR 6/ } \\
\text { R.Bat 1 }\end{array}$ & $\begin{array}{l}\text { ALR 6/ } \\
\text { R.Bat 3 }\end{array}$ \\
\hline \multirow{2}{*}{ Air heat pump } & PV size $\left(\mathrm{kW}_{\mathrm{p}}\right)$ & 1.6 & 1.6 & 4.9 & 4.9 & 4.9 & 9.9 & 9.9 & 9.9 \\
\cline { 2 - 10 } & Battery $(\mathrm{kWh})$ & - & 1.7 & - & 7.7 & 15.3 & - & 10.2 & 30.6 \\
\hline
\end{tabular}




\begin{tabular}{|c|c|c|c|c|c|c|c|c|c|}
\hline \multirow[t]{2}{*}{$\begin{array}{l}14400 \\
k W h_{\mathrm{e}} / \text { year }\end{array}$} & $\begin{array}{l}\text { PV electricity } \\
\text { self- } \\
\text { consumption }\end{array}$ & 89 & 96 & 58 & 82 & 91 & 37 & 57 & 68 \\
\hline & $\begin{array}{l}\text { Self- } \\
\text { sufficiency }\end{array}$ & 10 & 11 & 20 & 28 & 31 & 26 & 37 & 43 \\
\hline \multirow{4}{*}{$\begin{array}{l}\text { Direct electric } \\
\text { heating } \\
22500 \\
\text { kWh } / \text { /year }\end{array}$} & PV size $\left(k W_{p}\right)$ & 2.6 & 2.6 & 7.7 & 7.7 & 7.7 & 15.4 & 15.4 & 15.4 \\
\hline & Battery (kWh) & - & 2.6 & - & 11.7 & 23.4 & - & 15.6 & 46.8 \\
\hline & $\begin{array}{l}\text { PV electricity } \\
\text { self- } \\
\text { consumption }\end{array}$ & 75 & 86 & 46 & 68 & 74 & 30 & 47 & 55 \\
\hline & $\begin{array}{l}\text { Self- } \\
\text { sufficiency }\end{array}$ & 8 & 9 & 15 & 22 & 24 & 20 & 30 & 36 \\
\hline \multirow{4}{*}{$\begin{array}{l}\text { Pellet boiler } \\
7300 \mathrm{kWh}_{\mathrm{e}} / \text { year }\end{array}$} & PV size $\left(k W_{p}\right)$ & 0.8 & 0.8 & 2.5 & 2.5 & 2.5 & 5 & 5 & 5 \\
\hline & Battery (kWh) & - & 0.9 & - & 4 & 8.1 & - & 5.4 & 16.2 \\
\hline & $\begin{array}{l}\text { PV electricity } \\
\text { self- } \\
\text { consumption }\end{array}$ & 90 & 97 & 58 & 84 & 93 & 37 & 59 & 72 \\
\hline & $\begin{array}{l}\text { Self- } \\
\text { sufficiency }\end{array}$ & 11 & 12 & 21 & 31 & 34 & 27 & 43 & 53 \\
\hline
\end{tabular}

\subsection{Sensitivity analysis of the power rating}

Figures 8 shows the pp change in PV electricity self-consumption relative to the results presented in Figure 1 , for a reduction in power ratings in relation to a battery capacity of $0.25 \mathrm{E}$ (whereas in Figure 1. a value of $1 \mathrm{E}$ is used). As shown in Figure 8 , a decrease in power rating to $0.25 \mathrm{E}$ results in a decrease in PV electricity self-consumption of up to $4.1 \mathrm{pp}$, occurring at an ALR of 1 and relative battery capacity of 0.5 . This decrease has a substantial effect on PV electricity self-consumption, as the range for the increase in PV electricity self-consumption seen for this combination of ALR and relative battery capacity in Figure 1 is $0-10 \mathrm{pp}$. The impact of reducing the power rating is decreased with increasing relative battery capacity and increasing ALR, e.g., at an ALR of 3 and a relative battery capacity of 1 , a decrease of up to $1.5 \mathrm{pp}$ is observed. This decrease of $1.5 \mathrm{pp}$ should be compared to the range (15-25 pp) seen for this combination in Figure 1, this means that a power rating of $0.25 \mathrm{E}$ in this case leads to a reduction in PV electricity self-consumption of up to $10 \%$. Power ratings of $0.75 \mathrm{E}$ and $0.5 \mathrm{E}$ were also investigated. Decreasing the power rating to $0.75 \mathrm{E}$ has a minor impact on the PV electricity selfconsumption of the households for all cases. The largest decrease, $0.6 \mathrm{pp}$, occurs at an ALR of 1 and a relative battery capacity of 0.5 . Similar to the case with power rating of $0.25 \mathrm{E}$, the impact of reducing the power rating decreases with increasing relative battery capacity, although for relative battery capacities $>1$ the changes are small. For a power rating of $0.5 \mathrm{E}$, the same behavior is seen, although the maximum change becomes a decrease of $1.5 \mathrm{pp}$. On the 1-hour timescale of the data and with modeling applied, it can be concluded that the power rating of the battery has a minor or no impact on PV electricity self-consumption, and thus has negligible impact on self-sufficiency. There are simply sufficient hours of excess generation to replenish the battery's energy capacity during most days even if the power rating is decreased. The greater sensitivity to a decrease in power rating seen at lower ALRs is due to the fact that for these ALRs the duration of excess generation during a day is shorter. However, higher power ratings might be needed in order to manage intra-hour variations which are not captured by the model. 


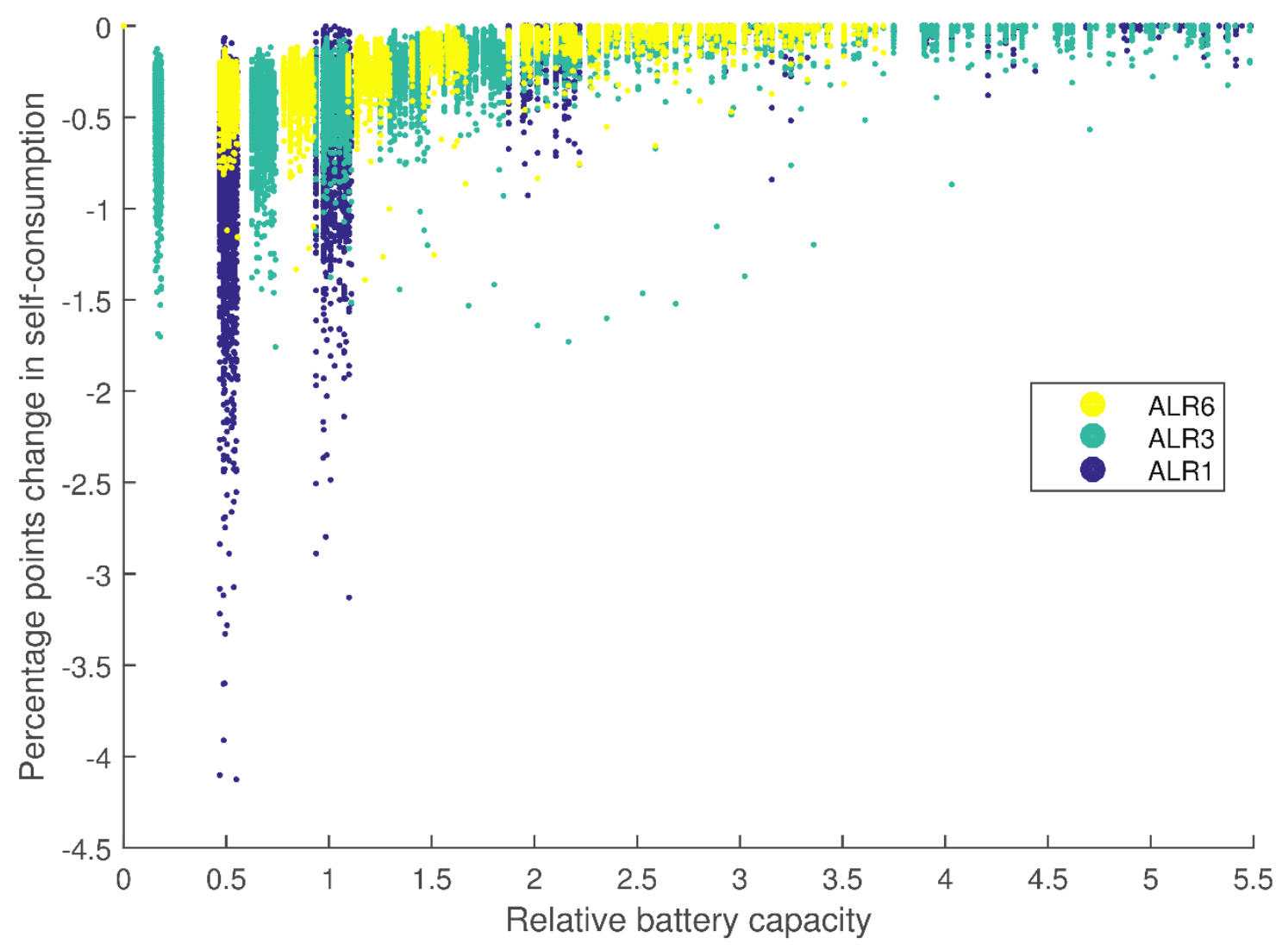

Figure 8. Percentage point change in PV electricity self-consumption for residential PV systems with battery storage with a power rating of $0.25 \mathrm{E}$ relative to a system systems with battery storage with a power rating of $1 \mathrm{E}$ (i.e. relative to the results presented in Figure 1) plotted against the relative battery capacity. Each point represents a modeled household and the color represents the ALR value.

\section{Discussion}

This work demonstrates that the optimal sizing of a battery and PV installation depends on the load profile of the household. Furthermore, it can be seen that there is a considerable variability between households in terms of how the installation of a battery increases PV electricity self-consumption and self-sufficiency. This indicates that an analysis of the household load profile should be performed, if possible, before the choice of battery capacity is made. Ultimately, the optimal choice of battery and PV capacities for a household obviously depend on the preferences of the household. A household that aims at a high degree of self-sufficiency will want to install both a large PV installation and a large battery. However, as shown in Figures 4 and 6 , increasing the relative battery capacity above the range of 2.5-4.0 confers virtually no improvement in self-sufficiency. Therefore, there is little value to be gained from the additional investment in battery capacity unless the battery can be used for arbitrage on the electricity market. Achieving $100 \%$ self-sufficiency would require enormous batteries that are able to store large amounts of energy across seasons, corresponding to a relative battery capacity in the hundreds, depending on the household.

This work does not include an economic assessment. Determining the economically optimal battery and PV capacities for a single household requires a comprehensive analysis, in which the investment cost of the PV-battery system is compared with the cost of buying all the required electricity from the grid. Moreover, the economic value of the battery could be increased further if there is potential to use the battery for arbitrage on the electricity market when it is not being used for shifting PV electricity. For both arbitrage and shifting of the PV electricity, a larger negative price difference between the hour of charging and the hour of discharging results in a higher economic value for the 
battery. Furthermore, as seen from the results presented in this study, the marginal value, in terms of PV electricity self-consumption, of adding battery capacity decreases with increasing battery size. This phenomenon holds true for the economic optimization of the battery system, i.e., the marginal economic value of increasing the battery capacity decreases with increasing battery capacity.

An issue with combining batteries and PV panels at northern latitudes, such as in Sweden, is the lower utilization time compared to southern Europe and locations closer to the equator. Due to the seasonal variations in solar PV output, batteries are not utilized during large parts of the year. However, as mentioned above, these batteries could be used for price arbitrage during these periods. In addition, the batteries could be made available to the power system, to provide ancillary services, for instance in the form of synthetic inertia to resist frequency changes in the event of a loss of generation or loss of load, and to provide primary, secondary or tertiary reserves, as the ramp-rates of batteries are generally fast $[29,30]$. For batteries to be able to provide these services they would obviously require participation in the system dispatch, i.e., the control of the batteries would have to be governed by either the market or some transmission system operator or utility, depending on the setup.

As no limit has been set for the depth of discharge in the model, the capacity of the actual installed battery will have to be greater than what is obtained from the results of this work. However, as shown by Battke et al. [28], the limits and optimal levels of depth of discharge depend on the cycle frequency of the battery and, thus, since there is a lack of consistent values for this it was excluded from the present study. Once a desired depth of discharge is determined, the battery capacities shown in the results presented in this work can be recalculated.

The use of hourly data in the model will have an impact on the results, as variations on a time-scale of less than 1 hour are filtered out. Intra-hourly loads can have a short time duration and require a fair amount of power, as in the case of an electric water boiler or a vacuum cleaner. Several studies, [12], Widén et al. [31] and Cao and Sirén [32], have shown that representing household load, as well as the combination of household load and PV generation with hourly resolution can lead to significant errors in the values for PV electricity self-consumption and self-sufficiency. This is especially the case for households in which the load and PV generation are of approximately the same magnitude. For larger PV installations, the error becomes smaller, as PV generation is larger than the fluctuations in demand. Furthermore, Cao and Sirén [32] have shown that introducing a battery essentially removes all the errors. They have shown that when modeling a PV installation of $2.7 \mathrm{~kW}_{\mathrm{p}}$, which is the PV capacity that showed the largest error between using a 1 hour or 1 minute time resolution in the modeling, a battery capacity of $0.5 \mathrm{kWh}$ is sufficient to reduce the error between the two time resolutions to a few percent. Similar conclusions are drawn by Beck et al. [12], they show that a 1 hour time resolution is sufficient when sizing the PV power and battery capacity. However, for sizing of the battery power they recommend a higher time resolution of $5 \mathrm{~min}$. Thus, the above mentioned influence of battery capacity on the error indicates that the largest error in the results presented in this study is for those cases without any batteries, especially the cases with lower ALRs. For these cases, the PV electricity selfconsumption and self-sufficiency can be overestimated. An overestimation in these cases means that the potential that any investment in a battery has for increasing the PV electricity self-consumption and self-sufficiency is underestimated, and is in fact larger than that shown here. However, this is only true when one compares to the case with no batteries, the differences between cases that use batteries should remain the same.

The potential need to balance intra-hour loads through the use of a battery requires higher E-values during charging and discharging than those required for hourly balancing, and if the load spikes are larger than the power output of the PV panel additional cycling of the battery is required. This indicates that the impact of reducing the E-value presented in this paper could be underestimated. Furthermore, 
as shown by Krieger and Arnold [33], higher E-values increase energy losses; thereby, the possible need for higher E-values would decrease the levels of self-sufficiency and PV electricity self-consumption presented in this paper. The extent of these losses would obviously depend on the number of load spikes in the household load curve. At larger battery capacities, an E-value of 1 should be sufficient to cover most intra-hourly power spikes, as they are seldom $>6 \mathrm{~kW}[31,32]$.

As the household loads are derived from measurements conducted over 1 year, the annual loads of households with electric heating loads may be over- or under-estimated, depending on whether it was a cold year or a hot year. However, in Year 2012, during which most of the measurements used in this work were obtained, the total electric heating demand deviated by only $0.5 \%$ from the 9 -year average (2006-2014) [34].

\section{Conclusions}

A model-based study using real-world household energy consumption data from 2,104 Swedish singlefamily dwellings was performed to investigate the extents to which a battery could help to increase PV electricity self-consumption (the amount of PV-generated electricity that is consumed in-house) and self-sufficiency (the fraction of electricity used by the household that is not bought from the grid) for PV installations in Swedish households. The modeling maximizes self-sufficiency, and thereby PV electricity self-consumption, for 122 different combinations of PV-panel and battery capacities for the 2,104 dwellings.

Given a relative battery capacity (defined as the battery energy storage capacity in kWh divided by the expected annual electricity output of the PV panels in MWh) of 2.5-4.0, a battery can increase PV electricity self-consumption by a practical maximum of 18-48 percentage points for Swedish households. As an example, for a household with an annual electricity consumption of $20 \mathrm{MWh}$ and a $\mathrm{PV}$ installation of $7 \mathrm{~kW}_{\mathrm{p}}$, this range in relative battery capacity would require batteries of considerable capacity, roughly 15-24 kWh (actual usable capacity). It is reasonable to assume that batteries in the above range (relative battery capacity of 2.5-4) is the maximum capacity to be installed in Swedish household with the purpose of increasing self-consumption and self-sufficiency. It is concluded that the ability of the battery to increase self-sufficiency increases with PV capacity, whereby the highest observed increase is about 30 percentage points for an installation with an ALR of 6 . It is also clear that the marginal value of a larger battery, in terms of PV electricity self-consumption and self-sufficiency, decreases rapidly at relative battery capacities greater than $2.5-4.0$. This is because the utilization time of each additional $\mathrm{kWh}$ is reduced, i.e., the battery is cycled fewer times. This effect particularly valid at Swedish latitudes due to the strong seasonality of PV generation, which requires energy to be shifted over long time-frames. Thus, significantly increasing the impact of batteries above the 18-48 percentage points for PV electricity self-consumption and 30 percentage points for self-sufficiency mentioned above would require considerably larger battery capacities due to the long time-frames needed for shifting.,.

The absolute levels of PV electricity self-consumption and self-sufficiency depend on the ALR, which relates the average household load during 1 year to the peak-Watt value of the installed PV system. For a household with average level of PV electricity self-consumption, the absolute value of PV electricity self-consumption at relative battery capacities of 2.5-4.0, which is the capacity at which the marginal benefit of additional batteries starts to become negligible, is in the range of $65 \%-100 \%$ (ALR 6.0-0.5), whereas for a household with average self-sufficiency, the corresponding value values are 5\%-45\% (ALR 0.5-6.0). Furthermore, the increase in absolute self-sufficiency shows diminishing returns with increasing ALR, since as the ALR increases most of the additional electricity generation occurs during hours of excess generation. 
At ALRs $<1.5$, the effect of increasing battery capacity on increasing PV electricity self-consumption declines, as compared to higher ALRs. This reduced impact is due to the lower number of hours of excess generation, as well as the fact that some households reach $100 \%$ PV electricity selfconsumption. For some households the reduced impact due to reaching $100 \%$ PV electricity selfconsumption can be seen up to an ALR of 4 .

It is also concluded from the present results that for an hourly time resolution, a battery power-toenergy ratio of up to 1:2, e.g., a power rating of $2 \mathrm{~kW}$ given a 4-kWh battery, is possible without having a major impact PV electricity self-consumption and self-sufficiency. However, at relative battery capacities $<2.5$ and a power-to-energy ratio of $1: 4$, the impacts on PV electricity self-consumption and self-sufficiency start to become significant.

\section{Acknowledgements}

This work is financed by the Chalmers-E.ON initiative.

\section{References}

[1] BP. BP Statistical Review of World Energy 2015. 2015.

[2] Nykvist B, Nilsson M. Rapidly falling costs of battery packs for electric vehicles. Nature Clim Change. 2015;5:329-32.

[3] Mulder G, Six D, Claessens B, Broes T, Omar N, Mierlo JV. The dimensioning of PV-battery systems depending on the incentive and selling price conditions. Applied Energy. 2013;111:1126-35.

[4] Tant J, Geth F, Six D, Tant P, Driesen J. Multiobjective battery storage to improve PV integration in residential distribution grids. IEEE Transactions on Sustainable Energy. 2013;4:182-91.

[5] Luthander R, Widén J, Nilsson D, Palm J. Photovoltaic self-consumption in buildings: A review. Applied Energy. 2015;142:80-94.

[6] Widén J, Munkhammar J. Evaluating the benefits of a solar home energy management system: impacts on photovoltaic power production value and grid interaction. eceee 2013 Summer Study, Presqu'île de Giens, France, June 3-8, 20132013.

[7] Thygesen R, Karlsson B. Simulation and analysis of a solar assisted heat pump system with two different storage types for high levels of PV electricity self-consumption. Solar Energy. 2014;103:1927.

[8] Weniger J, Tjaden T, Quaschning V. Sizing of residential PV battery systems. Energy Procedia. 2014;46:78-87.

[9] Mulder G, De Ridder F, Six D. Electricity storage for grid-connected household dwellings with PV panels. Solar Energy. 2010;84:1284-93.

[10] Pötzinger C, Preißinger M, Brüggemann D. Influence of Hydrogen-Based Storage Systems on SelfConsumption and Self-Sufficiency of Residential Photovoltaic Systems. Energies. 2015;8:8887.

[11] Linssen J, Stenzel P, Fleer J. Techno-economic analysis of photovoltaic battery systems and the influence of different consumer load profiles. Applied Energy. 2015.

[12] Beck T, Kondziella H, Huard G, Bruckner T. Assessing the influence of the temporal resolution of electrical load and PV generation profiles on self-consumption and sizing of PV-battery systems. Applied Energy. 2016;173:331-42.

[13] Johann A, Madlener R. Profitability of energy storage for raising self-consumption of solar power: Analysis of different household types in Germany. Energy Procedia. 2014;61:2206-10. [14] de Oliveira e Silva G, Hendrick P. Lead-acid batteries coupled with photovoltaics for increased electricity self-sufficiency in households. Applied Energy. 2016;178:856-67.

[15] Braun M, Büdenbender K, Magnor D, Jossen A. Photovoltaic self-consumption in Germany: using lithium-ion storage to increase self-consumed photovoltaic energy. 24th European Photovoltaic Solar Energy Conference (PVSEC), Hamburg, Germany2009. 
[16] Schreiber M, Hochloff P. Capacity-dependent tariffs and residential energy management for photovoltaic storage systems. 2013 IEEE Power \& Energy Society General Meeting: IEEE; 2013. p. 15 .

[17] Khalilpour KR, Vassallo A. Technoeconomic parametric analysis of PV-battery systems. Renewable Energy. 2016;97:757-68.

[18] Huang S, Xiao J, Pekny JF, Reklaitis GV, Liu AL. Quantifying System-Level Benefits from Distributed Solar and Energy Storage. Journal of Energy Engineering. 2012;138:33-42.

[19] Castillo-Cagigal M, Caamaño-Martín E, Matallanas E, Masa-Bote D, Gutiérrez A, MonasterioHuelin F, et al. PV self-consumption optimization with storage and Active DSM for the residential sector. Solar Energy. 2011;85:2338-48.

[20] Osawa M, Yoshimi K, Yamashita D, Yokoyama R, Masuda T, Kondou H, et al. Increase the rate of utilization of residential photovoltaic generation by EV charge-discharge control. IEEE PES Innovative Smart Grid Technologies: IEEE; 2012. p. 1-6.

[21] Widén J, Wäckelgård E, Lund PD. Options for improving the load matching capability of distributed photovoltaics: Methodology and application to high-latitude data. Solar Energy. 2009;83:1953-66.

[22] Norwood Z, Nyholm E, Otanicar T, Johnsson F. A Geospatial Comparison of Distributed Solar Heat and Power in Europe and the US. PloS one. 2014;9:e112442.

[23] King DL, Kratochvil JA, Boyson WE. Photovoltaic array performance model. United States. Department of Energy; 2004.

[24] Remund J. MSC. Solar Radiation and Uncertainty Information of Meteonorm 7. 26th European Photovoltaic Solar Energy Conference and Exhibition2011. p. 4388 - 90.

[25] Notton G, Lazarov V, Stoyanov L. Optimal sizing of a grid-connected PV system for various PV module technologies and inclinations, inverter efficiency characteristics and locations. Renewable Energy. 2010;35:541-54.

[26] Kamp S. Sveriges potential för elproduktion från takmonterade solceller [Master]. Uppsala: Uppsala Universitet; 2013.

[27] Jordan DC, Kurtz SR. Photovoltaic Degradation Rates-an Analytical Review. Progress in Photovoltaics: Research and Applications. 2013;21:12-29.

[28] Battke B, Schmidt TS, Grosspietsch D, Hoffmann VH. A review and probabilistic model of lifecycle costs of stationary batteries in multiple applications. Renewable and Sustainable Energy Reviews.

2013;25:240-50.

[29] Tielens $P$, Van Hertem D. The relevance of inertia in power systems. Renewable and Sustainable Energy Reviews. 2016;55:999-1009.

[30] Delille G, Francois B, Malarange G. Dynamic Frequency Control Support by Energy Storage to Reduce the Impact of Wind and Solar Generation on Isolated Power System's Inertia. Sustainable Energy, IEEE Transactions on. 2012;3:931-9.

[31] Widén J, Wäckelgård E, Paatero J, Lund P. Impacts of different data averaging times on statistical analysis of distributed domestic photovoltaic systems. Solar Energy. 2010;84:492-500.

[32] Cao S, Sirén K. Impact of simulation time-resolution on the matching of PV production and household electric demand. Applied Energy. 2014;128:192-208.

[33] Krieger EM, Arnold CB. Effects of undercharge and internal loss on the rate dependence of battery charge storage efficiency. Journal of Power Sources. 2012;210:286-91.

[34] The Swedish Energy Agency. Energy statistics for one- and two-dwelling buildings in 2014. 2015. 